\title{
Nitrogen-fixing bacteria and Oxalis - evidence for a vertically inherited bacterial symbiosis
}

\author{
Michelle Jooste $^{1 *}$ D, Francois Roets ${ }^{2}$, Guy F. Midgley ${ }^{1}$, Kenneth C. Oberlander ${ }^{3}$ and Léanne L. Dreyer ${ }^{1}$
}

\begin{abstract}
Background: Plant-endophyte symbioses often revolve around nitrogen metabolism, and involve varying degrees of intimacy. Although evidence for vertical inheritance of nitrogen-fixing endophytic bacteria is increasing, it is confined mostly to crop plants, and to date no such system has been reported for geophytes.

Methods: Bacterial endophytes associated with Oxalis, the most species-rich geophytic genus form the Cape Flora in southern Africa was studied. Culturable endophytes were isolated from surface-sterilized vegetative and reproductive plant organs for six host species at three locations. Colonies of microbes on various artificial media were morphotyped, enumerated and identified using sequence data. Filter exclusion experiments were conducted to determine if endophytes were vertically transmitted to seeds, determine if mucilage plays a role to actively attract microbes from the soil and to assess microbial richness isolated from the mucilage of Oxalis seedlings. Fluorescent microscopy was implemented in order to visualize endophytic bacteria in cryo-sectioned seeds.

Results: Evidence for a novel, vertically transmitted symbiosis was reported. Communities of nitrogen-fixing and plant growth-promoting Bacillus endophytes were found to associate with selected Oxalis hosts from nitrogen-deficient environments of the Cape. Bacillus endophytes were ubiquitous and diverse across species and plant bodies, and were prominent in seeds. Three common nitrogen-fixing Bacillus have known oxalotrophic properties and appear to be housed inside specialised cavities (containing oxalates) within the plant body and seeds.

Conclusions: The discovery of vertical transmission and potential benefits to both host and endophyte suggest a particularly tight mutualism in the Oxalis-endophyte system. This discovery suggests unexpected ways in which geophytes might avoid nitrogen deficiency, and suggest that such symbioses are more common than previously expected.
\end{abstract}

Keywords: Bacillus, Endophytic bacteria, Geophytes, Nitrogen fixation, Oxalotrophic bacteria, Oxalis, Vertical transmission

\section{Background}

The Greater Cape Floristic Region biodiversity hotspot (Cape) of southern Africa is globally renowned for its diverse and extremely species-rich flora $[1,2]$. To date at least some of this remarkable diversity has been attributed to abiotic factors such as palaeoclimatic stability, reliable seasonal water availability, geographical gradients and diverse soil types $[3,4]$. The sandstone derivation and low

\footnotetext{
* Correspondence: mich.jooste.m@gmail.com

${ }^{1}$ Department of Botany and Zoology, University of Stellenbosch, Private Bag X1, Matieland 7602, South Africa

Full list of author information is available at the end of the article
}

$\mathrm{pH}$ of most soils, together with predictable winter rainfall and relatively frequent wildfires all contribute to dystrophic conditions with severe nitrogen deficiency [4]. These include some of the lowest nitrogen and phosphorus levels measured globally [5]. Nitrogen is essential to the growth and development of all terrestrial plants [6-8]. There is growing evidence that diverse Cape plant lineages have adapted by forming associations with growth promoting and nitrogen-fixing micro-organisms [9]. Recently it has been suggested that plant-microbial interactions play an important role in generating, shaping and maintaining ecosystem diversity within the Cape $[10,11]$. Many of the

(C) The Author(s). 2019 Open Access This article is distributed under the terms of the Creative Commons Attribution 4.0 International License (http://creativecommons.org/licenses/by/4.0/), which permits unrestricted use, distribution, and 
most diverse and ecologically dominant indigenous Cape plant lineages form classical 'textbook' symbioses with beneficial micro-organisms [12-17]. Unfortunately, relatively little research attention has been given to these associations; it is evident that limited information is available addressing the mechanisms, diversity and role of microbial associations of Cape plants [18].

The Cape is also renowned for the most diverse geophyte flora in the world, including 2100 species from 20 families $[19,20]$. Although the factors driving this remarkable Cape geophyte diversity are still poorly understood, geographical distribution, climatic factors (rainfall quantity and reliability) and plant growth form (storage organ size) have been suggested [21]. The role of plant-microbial interactions has, however, not yet been confirmed [22].

Oxalis is the largest geophyte genus in the Cape (180 spp.), and has undergone an extensive radiation (ca. 230 spp.) in southern Africa [1,2] that likely originated in the Cape [23]. The evolutionary success of this genus in the Cape may partly be attributed to its unique life history, which includes a geophytic habit, winter flowering and variable seed strategies. However, the evolutionary success of this genus is still poorly understood. Cape Oxalis species are highly unusual in terms of their seed germination strategies as approximately $60 \%$ have recalcitrant seeds. These seeds germinate immediately when shed from fruits and display an inverted germination order compared to most angiosperms where foliar leaf development and growth followed by delayed radicle growth (Additional file 1: Figure S1). This remarkable germination strategy raises the question of how these seedlings are able to photosynthesize and grow without a well-developed radicle or roots. A set of observations that suggest that Oxalis has developed a unique association with nitrogen-fixing and/or growth promoting endophytic bacteria (EB) has been uncovered. Such associations may help explain the ecological (and evolutionary) success of Oxalis under challenging Cape edaphic conditions.

This study was focused on beneficial plant-microbial interactions and considered: 1) the presence of EB associated with Cape Oxalis species, 2) the EB community composition within hosts and between locations, and finally 3) elucidating the nature of relationships between host plants and endosymbionts.

\section{Results}

\section{Bacterial species found in vegetative and reproductive organs}

The presence and diversity of EB were assessed amongst vegetative and reproductive organs of six Oxalis host species sampled from three different locations (Fig. 1a). Pure-culture bacterial colonies isolated from sterilized, macerated plant material were identified using universal $16 \mathrm{~S}$ bacterial primers. Sequencing revealed that $92 \%$ of replicates were consistent with morphotyping, with all three replicates showing similar $16 \mathrm{~S}$ sequences with less than $2 \%$ base pair difference among sequences of approximately 800 base pairs. For the remaining two replicate sets, one sequence differed from the other two. This error margin $(2.6 \%$ of morphotypes incorrectly assigned), is small enough not to substantially affect the conclusions of this study. Sequencing was used to identify bacterial colonies from seeds and morphotype records were used to determine the distribution of bacterial species throughout the remainder of plant organs that were not sequenced.

A labile community of cultivable EB were associated with Oxalis hosts, where nine of the most abundant and consistent EB species were from the genus Bacillus. These species included B. aryabhattai Shivaji et al. 2009, B. bataviensis Heyrman et al. 2004, B. cereus/thuringiensis Frankland and Frankland 1887/Berliner 1915, B. licheniformis Weigmann 1898, B. megaterium de Bary 1884, B. mycoides Flügge 1886, B. safensis/pumilus Satomi et al. 2006/Meyer and Gottheil 1901, B. simplex Priest et al. 1989 emend. Heyrman et al. 2005/Sumpavapol et al. 2010 and B. subtilus/siamensis Cohn 1872. The most likely bacterial species identifications were based on $16 \mathrm{~S}$ sequences and phylogenetic comparison (Additional file 1: Figure S1).

Six bacterial endophytes were identified to species level and morphological traits (bacterial cell lengths) were used to distinguish between $B$. megaterium and $B$. aryabhattai that had unresolved relationships based on the consensus tree. There were three instances where it was not possible to distinguish between two closely related species. As these species are morphologically indistinguishable from one another, these endophytes were consequently referred to as $B$. cereus/thuringiensis, B. safensis/pumilus and B. subtilus/siamensis, indicating the two most likely identities of these isolates based on BLAST results. It should be noted that $B$. cereus and $B$. subtilus have previously been isolated from the rhizosphere and roots of two Oxalis species from Columbia [29] and were therefore considered as the most likely EB. More conclusive identification for these latter taxa requires additional markers.

Bacillus endophytes were identified from various host plant organs including roots, bulbs, stems, leaves and seeds, as well as the rhizosphere soil surrounding plant roots. Most (77.8\%) of the EB sampled from plant tissues were also present in the rhizosphere of the specific host plant studied. This suggests that these EB are a subset of rhizosphere bacteria. It is possible that the remainder of EB reached plants through colonization events during previous growing seasons, vertical transmission from 
parent plants or failure to isolate or identify specific EB during culturing either due to isolation protocol or EB was outcompeted by other stains on agar media. The majority of EB (91.1\%) occupied all sampled plant organs and all host species contained at least two EB species, across all recalcitrant and orthodox species. This indicated that these EB are generalist endophytes that are not host species-, organ- or germination strategyspecific. Sampling location may have influenced endophytic community composition, as one or two unique EB were isolated from each site or were shared among two sites (Fig. 1b). However, five out of the nine identified EB were shared among all three locations (Fig. 1c), indicating a universal association between Bacillus endophytes and Oxalis hosts.

It should be noted that seed bacterial diversity (Bacillus species) was a small subset (on average $25 \%$ ) relative to the total bacterial and fungal morphotype diversity isolated per plant (roots, bulbs, stems and leaves). The true endophytic diversity of bacteria and fungi colonising Oxalis hosts may be much larger than reported in this study.
EB were isolated from surface-sterilized, macerated seeds from all host species and locations. Multiple pureculture colonies isolated from the vegetative (roots, bulbs, leaves, stems) and seed tissues from a single host plant were sequenced using universal bacterial $16 \mathrm{~S}$ primers. Among $88.9 \%$ of studied cases identical sequences of EB isolates were obtained from parent plant and seed material. Isolation and identification of these EB indicated that vertical transmission from parent plants to their offspring would most likely explain this observation.

\section{Filter exclusion experiments to assess horizontal and vertical transmission}

Seeds and fruits from 230 angiosperm genera are known to excrete carbohydrate-rich mucilage around the seed coat and base of the hypocotyl [32]. Most recalcitrant Cape Oxalis species produce large amounts of mucilage upon germination. Filter exclusion experiments were conducted to assess if EB inhabit the mucilage of germinating seedlings, and to determine if additional microbes from the soil actively move towards the mucilage. Filters
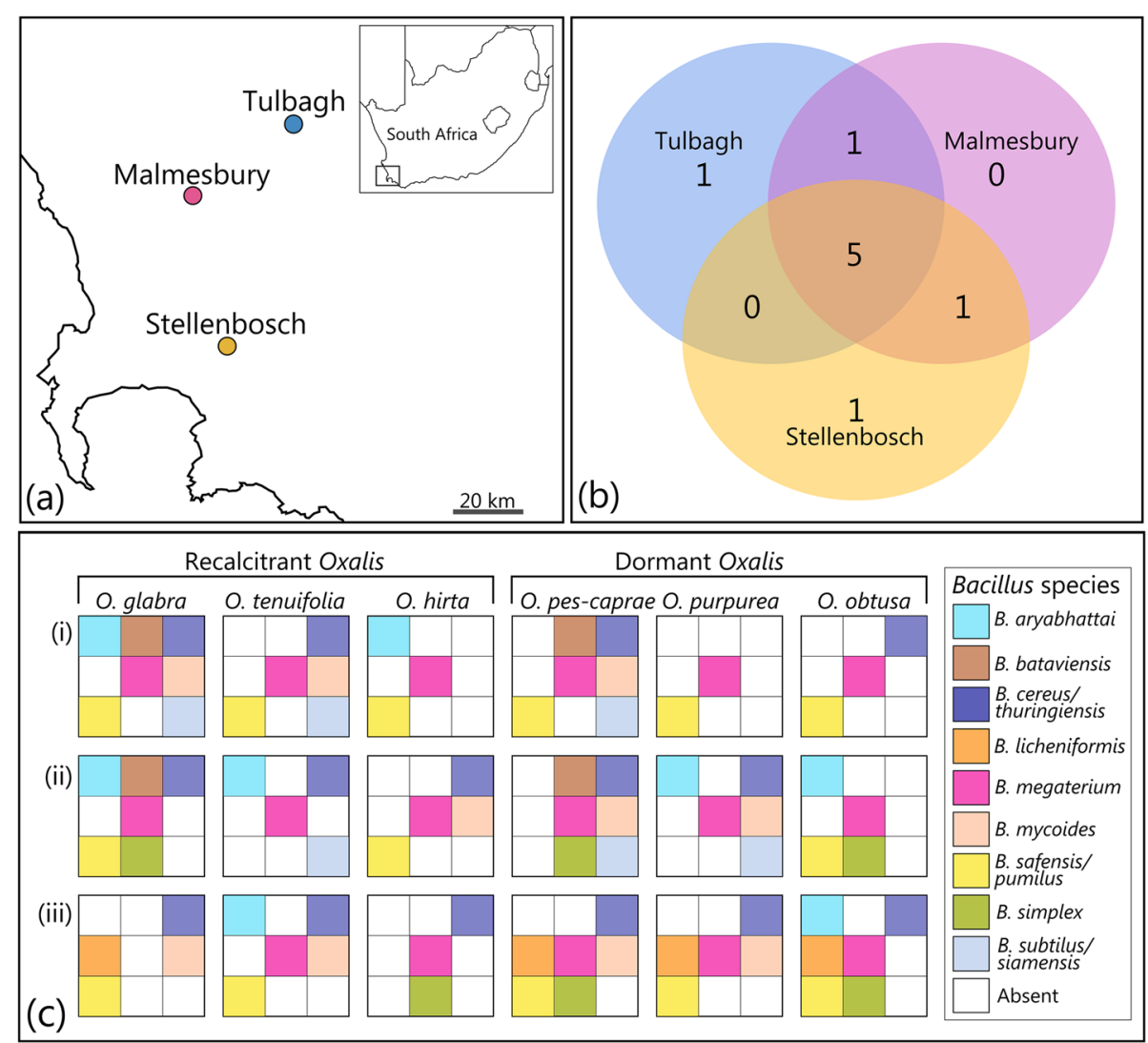

Fig. 1 Community composition and diversity of the most abundant and consistent endophytic bacteria (EB) isolated from Oxalis hosts. a Sampling locations within the Cape of southern Africa, $\mathbf{b}$ Unique and shared EB diversity across sampling locations, $\mathbf{c}$ Endophytic Bacillus species isolated from reproductive and vegetative plant organs (combined isolates from roots, bulbs, leaves, stems and seeds) and five plant replicates of six Oxalis hosts sampled at three locations: (i) Tulbagh, (ii) Malmesbury, (iii) Stellenbosch 
had an average pore size of $10-15 \mu \mathrm{m}$, while all identified $\mathrm{EB}$ had dimensions of $3.19 \times 1.33 \mu \mathrm{m}$ (length $\mathrm{SD}=$ $1.770 \mu \mathrm{m}$, width $\mathrm{SD}=0.671 \mu \mathrm{m})$.

Morphologically similar colonies were identified with a success rate of $97.4 \%$, with less than $2 \%$ base pair difference among sequences of approximately 800 base pairs. If morphologically new/unknown colonies were encountered they were given a unique morphotype number. Fungal isolates were documented and identified, but are not discussed in this article. Using the sequenced and identified EB from macerated plant material as reference material, this study has shown that the same suite of Bacillus species and no other cultivable bacteria were present in the mucilage of developing seedlings when germinated on sterile media
(Fig. 2a-b). The mean number of species obtained from both negative control treatments were significantly greater than zero (sterile agar mean $=1.67, \pm 1.118 \mathrm{SE}$; sterile soil mean $=1.89, \pm 1.150 \quad \mathrm{SE}, \mathrm{z}=4.592, p>$ 0.0001), confirming the presence of seed endophytes that were vertically transmitted from parent plants to their offspring. There was no significant difference between the number of species from the two sterile negative control treatments $(\mathrm{z}=0.908, p=0.795)$. The total diversity of vertically transmitted EB associated with each Oxalis host species (i.e. total bacterial species diversity across all within-species replicates) was higher than the average values reported for individual seedlings per species. Different combinations of EB species associated with individual seedling replicates.

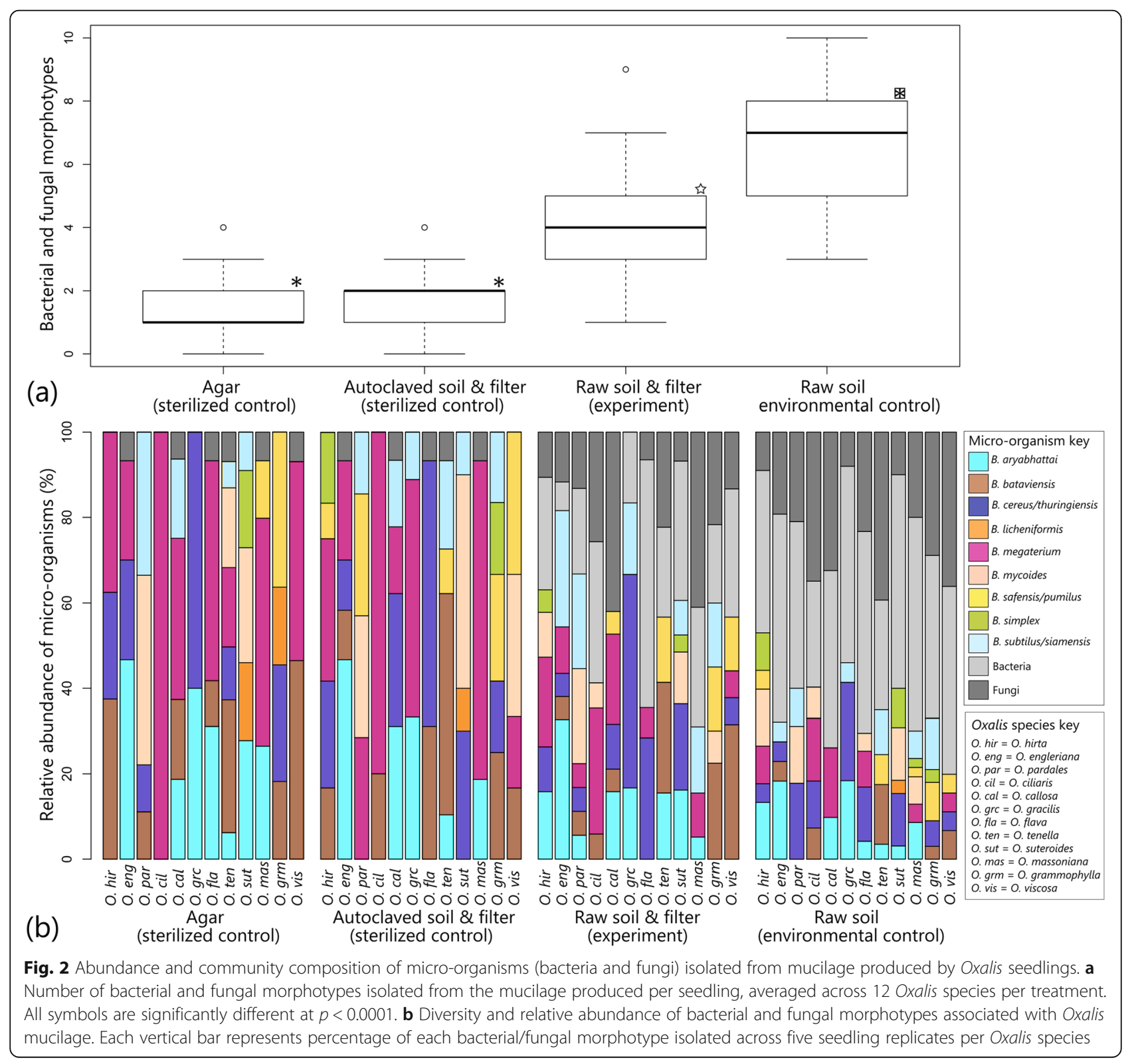


Environmental control treatments had the highest number of isolates per seedling (mean $=6.80, \pm 1.121 \mathrm{SE}$ ), while treatments with a filter had a significantly lower average number of isolates $($ mean $=4.08, \pm 1.129 \mathrm{SE}$ ) (Fig. 2a). Both the filter exclusion treatment and the environmental control had significantly higher microbial diversity $(\mathrm{z}=7.399$, $p<0.0001$ and $\mathrm{z}=12.343, p<0.0001$ respectively) relative to the negative controls. Sampling location may have had an effect on number of isolates, as the two Oxalis species sampled from the common garden collection had significantly fewer isolates per treatments (mean $=1.17, \mathrm{z}=-$ 2.363, $p=0.018$ ) than field-species. This may indicate a bottleneck effect in loss of microbial diversity in the garden soils or that unfavourable growth media were used to detect such EB if they were present. This experiment showed that a diverse assemblage of soil bacteria and fungi inhabit the mucilage of Oxalis seedlings, some which may be actively recruited from the rhizosphere and others provided (via vertical inheritance) by the seed itself (Fig. 2b).

\section{Potential plant growth promoting propertied if isolated EB}

Among bacterial species isolated from macerated Oxalis seeds, $90.9 \%$ were identified as EB with welldocumented growth promoting and/or nitrogen-fixing properties (Additional file 4: Table S1). This implies a possible role for selection favouring vertical transmission of beneficial endophytes. Three of the most prevalent endophytic species isolated from all Oxalis hosts and locations were the diazotrophic bacterial species $B$. cereus/thuringiensis, B. megaterium and B. safensis/pumilus (Fig. 1c). Symbiosis with diazotrophic and plant growth promoting EB can be considered a highly beneficial association from the host plant's perspective. Preliminary $\delta^{15} \mathrm{~N}$ data obtained from 83 Oxalis species illustrated a wide range of values $\left(16.78-2.09^{\circ} \%\right.$ o $)$, including relatively light values approaching the range reported for plants associated with N-fixing EB. However, due to limited sampling and lack of reference soil samples [33], this requires further testing. To our knowledge this is the first report of a potentially nitrogen-fixing association between EB and geophytes. Future research should explore the extent of $\mathrm{N}$-fixation in both seedlings and mature plants.

Potential benefits to the EB associates have not been tested, but could include a carbon-source for energy and housing inside Oxalis plant tissues. To date, nine EB have been isolated from four Oxalis species globally [34], and seven of these have known oxalotrophic properties. These include Azospirillum brasilense Krieg \& Döbereiner, 1978, B. amyloliquefaciens Priest et al. 1987, B. cereus, B. subtilis, B. vallismortis Roberts et al. 1996, Methylobacterium oxalidis Tani et al. 2012 and Serratia fonticola Gavini et al. 1979 [34, 35].
Oxalotrophic bacteria have the metabolic capacity to utilize oxalates as their only (and often preferred) carbon source $[35,36]$, and typically form symbioses in order to access these compounds. Oxalotrophic bacteria have been isolated from various habitats [37], but are most commonly found in the rhizosphere and roots of plants that excrete large amounts of oxalate. Oxalates most often occur in the form of oxalic acid or calcium oxalate crystals among members of the genus Rumex and Oxalis [37-39]. Due to the toxicity and low energy yield of oxalates, most microbes cannot utilize these as an energy source [35, 40].

\section{Discussion}

In this study three EB with known oxalotrophic activity were ubiquitous among Cape Oxalis: B. cereus/thuringiensis, B. licheniformis and B. subtilis. Importantly all three of these oxalotrophs have been reported as nitrogen-fixers, and at least one of each was isolated from the seeds of every sampled host plant. These findings could indicate a strong association between Oxalis plants and diazotrophic oxalotrophic EB. Vertical transmission typically evolves when symbiotic associations are mutualistic, in order to ensure that the beneficial endosymbionts are transferred from one generation to the next $[41,42]$. A recent study showed that oxalotrophic properties among $\mathrm{EB}$ were required to ensure colonization and transmission within host plants [43].

Oxalates are by-products of photorespiration [44] and high oxalate concentrations could be harmful to plant tissues, especially the photosynthetic system [45]. To avoid such damage, plants often compartmentalize oxalates as deposits within intracellular (ordinary cells or specialized crystal idioblasts) or extracellular structures (cavities) [46, 47]. Crystal idioblasts and cavities harbouring calcium oxalate crystals are well-documented in storage, vegetative and reproductive tissues of Oxalis [38, 48], including Cape Oxalis (Fig. 3a-e). Given that idioblasts and cavities are common among Oxalis species, and that oxalotrophic nitrogen-fixing EB were ubiquitous in Oxalis hosts, it is possible that endophytes might be housed inside these structures. That Oxalisassociated oxalotrophic EB would utilize oxalates as a carbon source, and in turn supply the hosts with biologically fixed nitrogen, is thus an intriguing possibility.

In this study the majority (95.5\%) of seeds with large and/or abundant idioblasts or cavities with oxalates were detected among embryo tissue of recalcitrant Oxalis species. It is possible that this structural adaptation, together with the mucilage production associated with germination, could help ensure that recalcitrant species host and transfer the beneficial endophytes to their seeds. Even though oxalotrophic diazotrophic EB were detected among all Oxalis species, it is likely that recalcitrant 


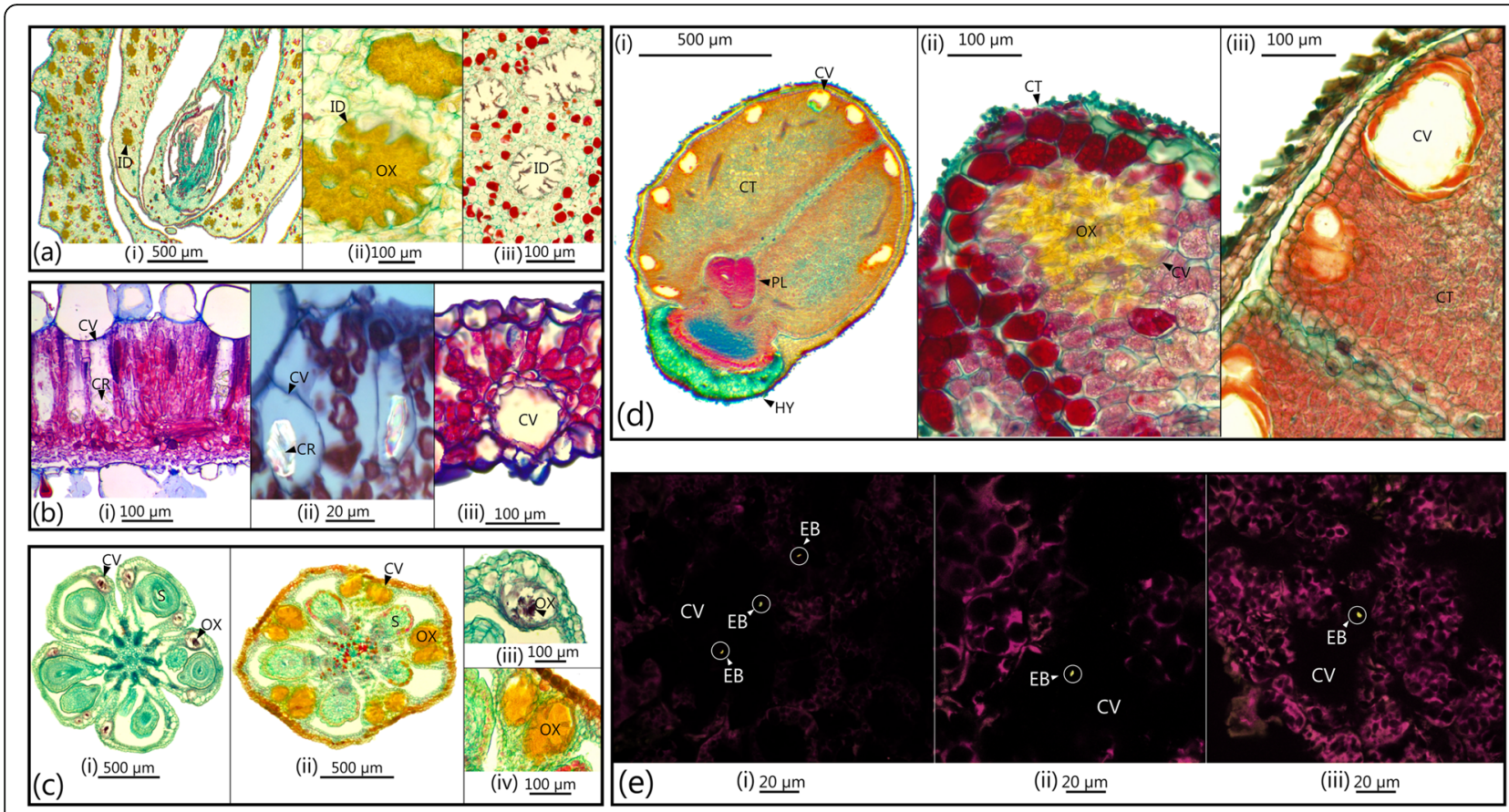

Fig. 3 Specialized idioblast cells and cavities containing oxalates, and potential endophytic bacteria within Cape Oxalis host plants. a Longitudinal sections through bulb fleshy leaves with idioblasts containing oxalates (crystals) (i,ii) and a cross section of empty cavities (iii). $\mathbf{b}$ Cross sections of photosynthetic leaves with cavities containing oxalates (i,ii) and empty cavities with an epithelial lining (iii). c Cross sections of dormant (i) and recalcitrant (ii) fruit capsules with cavities containing oxalates. $\mathbf{d}$ Longitudinal sections of recalcitrant seeds with multiple cavities in the cotyledons (i), a cavity containing oxalates (ii) and empty cavities with epithelial lining (iii). e Confocal staining of cross sections of sterilized seeds indicating bacteria (bright green rods, circled in white) inside cavities. Original red-and-green confocal images supplied in Additional file 3: Figure S3. EB = endophytic bacteria, $\mathrm{CO}=$ cotyledon, $\mathrm{CR}=$ crystals, $\mathrm{CV}=$ cavities, $\mathrm{HY}=$ hypocotyl, ID = idioblasts or idioblast cavities, $\mathrm{OX}=\mathrm{Oxalates}, \mathrm{PL}=$ plumule, $\mathrm{S}=$ seeds. A key to all species names is provided in Additional file 5: Table $\mathbf{S 2}$

seedlings may be most reliant on these associations given their inverted germination sequence. Additional nitrogen could lessen the need for immediate root growth, which could allow a resource allocation shift from root germination to leaf growth instead. It is possible that an association with EB were a pre-adaptation to such an unusual inversed sequence of germination and rapid growth and establishment of seedlings.

If shown to have benefit to the host, such a widespread association with EB could be a key mechanism that allows Oxalis to thrive and diversify in such nutrientdepleted environments as those present in the Cape. The discovery of this symbiosis could hold critical implications for the current understanding of the distribution of Oxalis, its anatomy and physiology, the establishment of seedlings and evolution of this genus within the Cape Flora. Given the lack of data for endophytic associations in other geophytes, this may be a more widespread phenomenon in the Cape and globally. This knowledge is also directly relevant to all conservation efforts, invasion biology and predictions of the expected response of this genus and other Cape plants under current climate change predictions.
Most importantly, all of these EB strains were isolated from surface-sterilized Oxalis seeds, illustrating vertical transmission from parent plants to the next generation. To date, growth promoting and nitrogen-fixing seed endophytes have been recorded among well-studied crop plants $[49,50]$, but are rarely documented among wild plants [51]. The confirmation that nitrogen-fixing EB are vertically transmitted among geophytes indicates that it may be a far more widespread phenomenon than previously thought. To date the only other known examples of vertical transmission of diazotrophic bacteria occur in the giant cordon cactus (Pachycereus pringlei S. Watson) [52] and an invasive grass (Sorghum halepense L.) [53], both from North America.

The many beneficial traits associated with diazotrophic and/or oxalotrophic seed EB could be used for applications in natural and agricultural systems, especially for plants grown in harsh and nutrient-depleted conditions $[54,55]$. Bacillus species are widely known to be safe and highly effective when used to enhance crop growth and yield [56]. The roles and importance of nitrogen-fixing EB capable of vertical transmission, represents a fascinating, yet largely understudied aspect of the Cape Flora. 


\section{Conclusions}

The discovery of vertical transmission of Bacillus endophytes from parent plants to the next generation and potential benefits to both host and endophyte, suggest a particularly tight mutualism in the Oxalis-endophyte system. Given that idioblasts and cavities are common among Oxalis species, and that oxalotrophic nitrogenfixing EB were ubiquitous in Oxalis hosts, it is possible that endophytes might be housed inside these structures. This discovery also suggests unexpected ways in which geophytes might avoid nitrogen deficiency, and suggest that such symbioses are more common than previously expected.

\section{Methods}

\section{Oxalis plant material and sterilization protocol}

Six phylogenetically representative Oxalis species (O. glabra Thunb., O. hirta L., O. obtusa Jacq., O. pes-caprae L., O. purpurea L. and O. tenuifolia Jacq.) were sampled from three locations (Malmesbury [-33.481121, 18.753625], Stellenbosch [-33.932358, 18.874571] and Tulbagh [-33.311688, 19.096747]) in the Western Cape Province, South Africa. All plants were correctly identified and harvested from the wild (research sample collection permit obtained from the Western Cape Nature Conservation Board, South Africa). Five individuals of each species (at least $10 \mathrm{~m}$ apart), with no external signs of microbial infections (asymptomatic), were collected at each location during May-June of 2016 and 2017. Plants were dug out with minimal disturbance to the belowground organs and all excess soil was shaken off, until no soil was visible on roots and bulbs. Before samples were processed for endophyte isolation, plant roots were gently washed in $5 \mathrm{ml}$ sterile water in order to obtain rhizosphere samples. Hereafter roots, bulbs, stems/rhizomes (depending on the above-ground growth forms of species: O. glabra, O. hirta and O. tenuifolia have above ground stems; $O$. pes-caprae, $O$. purpurea and the sampled populations of O. obtusa do not), leaves and seeds of all plants were aseptically separated using a scalpel and individually surface sterilized. For surface sterilization, samples were washed in a $33 \%$ dilution of household bleach ( $\pm 5 \%$ sodium hypochlorite) for $1 \mathrm{~min}$ and $75 \%$ ethanol for $1 \mathrm{~min}$, interspersed with three oneminute washes in sterile water. As sterilization controls a few additional samples of each of the plant organs were dabbed onto bacterial plate count agar (Biolab, Merck) and malt extract agar (Sigma-Aldrich), and incubated for 7 days at $28^{\circ} \mathrm{C}$ in the dark - no colonies were detected.

\section{Isolation of bacterial colonies}

Plant organs were manually cut into small segments using a scalpel and transferred into Eppendorf tubes (to the $0.5 \mathrm{~mL}$ mark) with five sterile glass beads and sterile water to $1.5 \mathrm{~mL}$, under sterile conditions. Samples were macerated using a TissueLyser (Qiagen TissueLyser, Retsch MM301) at the Central Analytical Facility at Stellenbosch University. $200 \mu \mathrm{L}$ each of 1:4 sterile-waterdiluted macerate was plated onto three agar media: bacterial plate count agar (Biolab, Merck), nutrient broth agar (Sigma-Aldrich) emended with $4 \mathrm{~g}$ potassium oxalate (BMS Education) per litre of agar and malt extract agar (Sigma-Aldrich). Potassium oxalate was added to nutrient broth agar to re-create the high oxalate content of the host plant (as described by Sahin (2005); agar medium with $\mathrm{pH}$ 5.51). After 5 days of incubation at $28^{\circ} \mathrm{C}$ in the dark, all morphologically different colonies (in terms of colour, shape, size and/or texture) were sub-cultured onto fresh plates. This process was repeated after another 5 days of incubation for each identified morphotype until pure cultures were obtained. All bacterial morphotypes were recorded and photographed. Three individuals of each morphotype per Oxalis species from each location were kept to test accuracy of morphotype identification. Each representative morphotype was divided, with 50\% used for DNA extraction and sequencing, and the remainder stored in 50\% glycerol in cryostorage $\left(-80^{\circ} \mathrm{C}\right)$.

\section{DNA extraction, amplification and sequencing}

To assess accuracy of endophyte morphotyping, three replicates from 25 different bacterial morphotypes were sequenced, with the expectation that the DNA sequences of each morphotype triplet would be identical. Morphotypes isolated from seeds and bulbs (reproductive propagules) were prioritized for sequencing in this study. DNA extractions were done following a modified 2X CTAB protocol, as described in Oberlander et al. [24]. Amplification and sequencing of the $16 \mathrm{~S}$ rRNA region was conducted using universal bacterial primers 27F (5'-AGAGTTTGATCMTGGCTCAG-3') and 1492R (5' -ACCTTGTTACGACTT-3') [25]. PCR amplification reactions were performed using $25 \mu \mathrm{L}$ reaction mixtures consisting of $9 \mu \mathrm{L} \mathrm{dH} 2 \mathrm{O}, 2.5 \mu \mathrm{L} \mathrm{MgCl}_{2}$ (25 $\mathrm{mM}), 0.25 \mu \mathrm{L}$ of each primer $(10 \mu \mathrm{M}), 12 \mu \mathrm{L}$ KapaTAQ (KM1000, Kapa Biosystems) and $1 \mu \mathrm{L}$ DNA (326 to 498 $\mathrm{ng} / \mu \mathrm{L})$. The PCR thermal cycling conditions were: $94{ }^{\circ} \mathrm{C}$ (5 min), 30 cycles of $94{ }^{\circ} \mathrm{C}(1 \mathrm{~min}), 49^{\circ} \mathrm{C}(1 \mathrm{~min})$ and $72{ }^{\circ} \mathrm{C}$ (2 min), with final extension at $72^{\circ} \mathrm{C}(10 \mathrm{~min})$. PCR products were sequenced at the Central Analytical Facility at Stellenbosch University. Confirmation of base calling in sequence chromatograms was manually conducted in Chromas v. 2.6.5 (http://www.technelysium. com.au). Sequences were aligned using the embedded ClustalW function [26] in BioEdit v. 7.2.6 [27]. Obtained sequences were compared to GenBank (NCBI) submissions using online BLAST searches. 


\section{Phylogenetic analysis}

Phylogenetic trees were reconstructed using a dataset of $16 \mathrm{~S}$ sequences for endophytic bacteria (excluding duplicate sequences), sequences downloaded from Genbank (three representative BLAST results per Oxalis endophyte sequence) as well as four bacterial outgroup species. Tree samples were generated in MrBayes (v. 3.2) using the nst $=$ mixed command for model selection and a gamma rate correction for $2 \times 10^{7}$ generations under otherwise default settings. Convergence of parameter values was checked in Tracer (v.1.6) [28] 25\% burnin. The consensus tree was used to aid species identification (Additional file 1: Figure S1).

\section{Filter exclusion experiments}

The aim of these experiments was to determine if $E B$ were transmitted from parents to seedlings (vertical transmission) and determine if mucilage plays a role to attract additional microbes from the soil (horizontal transmission). Filter exclusion experiments were conducted to assess microbial richness isolated from the mucilage of Oxalis seedlings. Sterilized gel drying frames (Sigma-Aldrich) were used as a filter barrier between the germinating seed and a selected treatment medium. The pore size $(10-15 \mu \mathrm{m})$ of these filters was large enough to allow movement of microorganisms through the filter. Filters were wet with sterile water in order to prevent an artificial pulling-effect when seeds with mucilage were placed on the filters. Experimental filter treatments were compared to two negative controls (sterile conditions) and one positive environmental control (soil).

Mature seeds were harvested from 12 recalcitrant Oxalis species (20 seeds per species) that are known to produce large amounts of hypocotylar mucilage. For each species, a soil sample (10x10 $\mathrm{cm}$ and $5 \mathrm{~cm}$ deep) was collected at each sampling location (10 species sampled from filed locations and 2 species sampled from a research collection at the Stellenbosch University Botanical gardens). A research sample collection permit was obtained from the Western Cape Nature Conservation Board, South Africa for all seeds harvested from the wild. Seeds were surfacesterilized according to the above-mentioned protocol. Seeds were randomly divided into four groups of five seeds each and assigned to one of four experimental treatments. Treatment 1 served as a negative control where seeds were placed on sterile agar. Treatment 2 served as an additional negative control where seeds were placed on a sterilized filter and a sample of autoclaved soil within a sterile petri-dish. Treatment 3 consisted of a sample of raw soil within a petri dish with a sterilized filter placed on top. Seeds were then placed on top of the filter to determine if microbes actively move towards the mucilage. Treatment 4 served as a positive environmental control where seeds were placed on a sample of untreated raw soil to determine if microbes passively move towards the mucilage through direct contact between the seed mucilage and the soil. After 3 days of exposure to treatments, each seed was individually removed and the mucilage around the base of the hypocotyl was lightly streaked across one bacteriological and one fungal agar growth medium under sterile conditions. Isolates were subcultured to obtain pure culture colonies of each identified morphotype, as described in the protocol above. Morphotypes were visually compared to a reference database created from all sequenced microbes (as described in the section above).

The total number of unique microbial morphotypes was recorded in order to assess microbial richness associated with the mucilage of all seeds exposed to the four treatments. Microbial morphotype count data were analysed with the best fitting generalized linear mixed effects model using the lme4 package [30] in the R statistical environment, version 3.4.1 (R-Core-Team, 2014). Treatment type and sampling location were entered as fixed effects and Oxalis host species as a random effect. Residual plots did not reveal any obvious deviations from normality or homoscedasticity. A post-hoc Tukey test was used to compare estimated values between the four treatment groups.

\section{Seed, seedling and plant anatomy}

All Oxalis bulb, leaf, seed and seedling material (sampled from a research collection and the wild) was fixed in Formalin-Acetic-Acid-Alcohol (FAA), dehydrated in an alcohol series and gradually infiltrated with and embedded in paraffin wax [31]. Samples were sectioned with a rotary microtome (Leitz, Germany). Sections were stained using the Safranin-Alcian-blue or Safranin-Fastgreen differential staining methods [31] and DPX glue was used to preserve these sections as permanent slides. Anatomical traits of embedded plant material were studied using a Nikon ECLIPSE E400 light microscope and photographed using a Leica MC $170 \mathrm{HD}$ camera and LAS CORE software (Leica, Switzerland). Seedling germination and growth were documented using Leica M125 stereo microscope and LAS CORE software. Backgrounds of images and plant debris from preparing slides were removed using the 'fuzzy select tool' from Gimp 2.10.2.

Fresh Oxalis seeds were surface sterilized following the above-mentioned protocol, embedded and cryosectioned using a Leica CM1860 UV cryostat (Leica Biosystems). All seeds were harvested from the wild Oxalis populations growing at Stellenbosch. Sections were mounted on sterilized glass slides. Sectioning and staining were done on the same days as seed harvest. Slides were stained with LIVE/DEAD BacLight Bacterial Viability Kit (Life Technology), using $100 \mu \mathrm{L}$ per slide. Slides were viewed using a Carl Zeiss Confocal LSM 780 Elyra 
S1 microscope from the Fluorescence Microscopy Unit (Central Analytical Facility) at Stellenbosch University, in order to detect the location of bacteria within seeds. Original red and green light fluorescence images have been changed to a colour-safe combination of magenta and lime-green (Fig. 3di-iii), using the 'colour shift function' $\left(310^{\circ}\right.$ to $\left.319^{\circ}\right)$ in Inkscape 0.92 .3 .

\section{Supplementary information}

Supplementary information accompanies this paper at https://doi.org/10 1186/s12870-019-2049-7.

Additional file 1: Figure S1. Seedling germination and development of recalcitrant Cape Oxalis, where foliar leaf development and growth is followed by delayed radicle growth. O. clavifolia Sond. (a) and O. glabra Thunb. (b) one (i), three (ii), five (iii) and 10 (iv) days after germination. All seedlings oriented with radicle pointing to bottom of figure. $\mathrm{CT}=$ cotyledons, $\mathrm{FL}=$ foliar leaf, $\mathrm{RD}=$ radicle.

Additional file 2: Figure S2. Phylogenetic consensus tree constructed with universal 165 region sequences for endophytic bacteria isolated from Cape Oxalis (boldface font) and representative GenBank BLAST results. Colour boxes indicate the most likely species identifications of Oxalis isolates. B. megaterium and B. aryabhattai that had unresolved relationships based on the consensus tree.

Additional file 3: Figure S3. Original red-and-green confocal staining images of cross sections of sterilized Oxalis seeds indicating bacteria (bright green rods) inside cavities. (i-ii) O hirta, (iii) $O$. pes-caprae.

Additional file 4: Table S1. Properties of bacterial endophytes isolated from Oxalis host plants, as described in literature [57-67].

Additional file 5: Table S2. A key to all species names relating to Fig. 2.

\section{Abbreviations}

EB: Endophytic bacteria; N- fixation: Nitrogen fixation

\section{Acknowledgements}

We thank Stellenbosch University and the Department of Botany and Zoology for facilities and equipment. We thank the Fluorescence Microscopy Unit (Central Analytical Facility) at Stellenbosch University with assistance with confocal microscopy and the Western Cape Nature Conservation Board for a research sample collection permit.

\section{Authors' contributions}

All authors designed the research. MJ conducted most of the research, with some field and laboratory assistance from LLD. Data analysis was done by $\mathrm{MJ}$, with input and assistance from KCO. All authors contributed equally to data interpretation. MJ wrote the paper and FR, GFM, KCO and LLD commented on two drafts thereof. All authors have read and approved this manuscript.

\section{Funding}

We thank the National Research Foundation for the Scarce Skills Doctoral Scholarship (awarded to M.J.) and National Research Foundation Blue Skies Research Grant (awarded to L.L.D.). These grants provided financial support for this study, but these funding bodies did not play any role in the design of the study, the collection, analysis, and interpretation of data or writing the manuscript.

\section{Availability of data and materials}

The datasets supporting the conclusions of this article are included within the article and its additional files (Additional file 1: Figure S1, Additional file 2: Figure S2, Additional file 3: Figure S3, Additional file 4: Table S1 and Additional file 5: Table S2).

\section{Ethics approval and consent to participate}

Experimental research on plants, including collection of plant material, complied with institutional and national guidelines. Field studies were conducted in accordance with local legislation and Oxalis research sample collection permit was obtained from the Western Cape Nature Conservation Board, South Africa.

\section{Consent for publication}

Not applicable.

\section{Competing interests}

The authors declare that they have no competing interests.

\section{Author details}

${ }^{1}$ Department of Botany and Zoology, University of Stellenbosch, Private Bag X1, Matieland 7602, South Africa. ${ }^{2}$ Department Conservation Ecology and Entomology, University of Stellenbosch, Private Bag X1, Matieland 7602, South Africa. ${ }^{3}$ H. G. W. J. Schweickerdt Herbarium, Department of Plant and Soil Sciences, Plant Sciences Complex, University of Pretoria, Private Bag X20, Hatfield 0028, South Africa.

Received: 17 November 2018 Accepted: 20 September 2019

Published online: 23 October 2019

\section{References}

1. Manning JC, Goldblatt P. Plants of the Greater Cape Floristic Region 1: the core cape region. Pretoria: South African National Biodiversity Institute; 2012

2. Snijman DA. Plants of the Greater Cape Floristic Region volume 2: the extra Cape Flora. Pretoria: South African National Biodiversity Institute; 2013.

3. Jansson R. Global patterns in endemism explained by past climatic change. Proc R Soc Lond B Biol Sci. 2006:270:583-90.

4. Mucina L, Rutherford MC. The vegetation of South Africa, Lesotho and Swaziland. Pretoria: South African National Biodiversity Institute; 2006.

5. Specht RL, Moll EJ. Mediterranean-type heathlands and sclerophyllous shrublands of the world: an overview. In: Mediterranean-type ecosystems. Berlin: Springer; 1983. p. 41-65.

6. Olson RA, Kurtz LT. Crop nitrogen requirements, utilization and fertilization. In: Nitrogen in Agricultural Soils; 1982. p. 567-604.

7. Raven JA. The iron and molybdenum use efficiencies of plant growth with different energy, carbon and nitrogen sources. New Phytol. 1988;109:279-28.

8. Rustad LE, Campbell J, Marion G, Norby R, Mitchell M, et al. A meta-analysis of the response of soil respiration, net nitrogen mineralization, and aboveground plant growth to experimental ecosystem warming. Oecologia. 2001;126:543-62.

9. Cowan DA, Rybicki EP, Tuffin MI, Valverde A, Wingfield MJ. Biodiversity: so much more than legs and leaves. S Afr J Sci. 2013;109:1-9.

10. Miyambo T, Makhalanyane TP, Cowan DA, Valverde A. Plants of the fynbos biome harbour host species-specific bacterial communities. FEMS Microbiol Lett. 2016:363:15.

11. van der Heijden MGA, Bardgett RD, Van Straalen NM. The unseen majority: soil microbes as drivers of plant diversity and productivity in terrestrial ecosystems. Ecol Lett. 2008;11:296-310.

12. Lamont B. Mechanisms for enhancing nutrient uptake in plants, with particular reference to mediterranean South Africa and Western Australia. Bot Rev. 1982;48:597-689.

13. Moulin L, Munive A, Dreyfus B, Boivin-Masson C. Nodulation of legumes by members of the $\beta$-subclass of Proteobacteria. Nature. 2001;411:948.

14. Elliott GN, Chen WM, Bontemps C, Chou JH, JP Y, et al. Nodulation of Cyclopia spp. (Leguminosae, Papilionoideae) by Burkholderia tuberum. Ann Bot. 2007:100:1403-11.

15. Hassen Al, Bopape FL, Habig J, Lamprecht SC. Nodulation of rooibos (Aspalathus linearis Burm. f.), an indigenous South African legume, by members of both the a-Proteobacteria and $\beta$-Proteobacteria. Biol Fertil Soils. 2012;48:295-303.

16. Allsopp N, Holmes PM. The impact of alien plant invasion on mycorrhizas in mountain fynbos vegetation. S Afr J Bot. 2001;67:150-6.

17. Stafford WH, Baker GC, Brown SA, Burton SG, Cowan DA. Bacterial diversity in the rhizosphere of Proteaceae species. Environ Microbiol. 2005;7:1755-68.

18. Allsopp N, Stock WD. Mycorrhizal status of plants in the Cape floristic region, South Africa. Bothalia. 1993;23:91-104.

19. Proches \$, Cowling RM, Goldblatt P, Manning JC, Snijman DA. An overview of the Cape geophytes. Biol J Linn Soc. 2006;87:27-43.

20. Cowling R, Logie C, Snijman D, Potgieter GA. A tale of two floras: bulb capitals of the east and west. Veld Flora. 2009;95:70-3. 
21. Procheş Ş, Cowling RM, Preez DR. Patterns of geophyte diversity and storage organ size in the winter-rainfall region of southern Africas. Divers Distrib. 2005;11:101-9.

22. Waterman RJ, Bidartondo MI, Stofberg J, Combs JK, Gebauer G, Savolainen V, Barraclough TG, Pauw A. The effects of above-and belowground mutualisms on orchid speciation and coexistence. Am Nat. 2011:177:e54-68.

23. Oberlander KC, Dreyer LL, Bellstedt DU. Molecular phylogenetics and origins of southern African Oxalis. Taxon. 2011;60:1667-77.

24. Oberlander KC, Dreyer LL, Bellstedt DU. Systematic relationships in southern African Oxalis L.(Oxalidaceae): congruence between palynological and plastid trnL-F evidence. Taxon. 2004;53:977-85.

25. Weisburg WG, Barns SM, Pelletier DA, Lane DJ. 16 S ribosomal DNA amplification for phylogenetic study. J Bacteriol. 1991;173:697-703.

26. Thompson JD, Higgins DG, Gibson TJ. CLUSTAL W: improving the sensitivity of progressive multiple sequence alignment through sequence weighting position-specific gap penalties and weight matrix choice. Nucleic Acids Res. 1994:22:4673-80.

27. Hall TA. BioEdit: a user-friendly biological sequence alignment editor and analysis program for Windows 95/98/NT. Nucleic Acids Symp Ser. 1999:41:95-8.

28. Rambaut A, Drummond AJ, Xie D, Baele G, Suchard MA. Posterior summarisation in Bayesian phylogenetics using Tracer 1.7. Syst Biol. 2018:syy032.

29. Castillo-Arteaga RD, Fernández-Izquierdo P. Degradación de oxalato por bacterias oxalotróficas asociadas a plantas del género Oxalis sp en regiones Andinas del departamento de Nariño. Univ Health. 2016;18:69-78.

30. Bates D, Sarkar D, Bates MD, Matrix L. The Ime4 package. $R$ package version, 2:1; 2007. p. 74.

31. Johansen DA. Plant microtechique. London: McGraw-Hill Book Company Inc.; 1940

32. Yang X, Baskin JM, Baskin CC, Huang Z. More than just a coating: ecological importance, taxonomic occurrence and phylogenetic relationships of seed coat mucilage. Perspect Plant Ecol Evol Syst. 2012;14:434-42.

33. Hogberg P. ${ }^{15} \mathrm{~N}$ natural abundance in soil-plant systems. New Phytol. 1997 137:179-203.

34. Sahin N. Oxalotrophic bacteria. Res Microbiol. 2003;154:399-407.

35. Sahin N, Gökler I, Tamer AÜ. Isolation, characterization and numerical taxonomy of novel oxalate-oxidizing bacteria. J Microbiol. 2002;40:109-18.

36. Dimroth $\mathrm{P}$, Schink B. Energy conservation in the decarboxylation of dicarboxylic acids by fermenting bacteria. Arch Microbiol. 1998;170:69-77.

37. Tamer AU, Aragno M, Jenni B. Genomic relation among nine strains of oxalate utilizing bacteria. Turk J Biol. 1993;17:115-9.

38. Seal SN, Sen SP. The photosynthetic production of oxalic acid in Oxalis corniculata. Plant Cell Physiol. 1970;11:119-28.

39. Peng A, Liu J, Gao Y, Chen Z. Distribution of endophytic bacteria in Alopecurus aequalis Sobol and Oxalis corniculata L from soils contaminated by polycyclic aromatic hydrocarbons. PLoS One. 2013;8:e83054.

40. Mufti R, Amna Rafique M, Haq F, Hussain MF, Munis Masood S, et al. Genetic diversity and metal resistance assessment of endophytes isolated from Oxalis corniculata. Soil Environ. 2015:34:89-99.

41. Herre EA, Knowlton N, Mueller UG, Rehner SA. The evolution of mutualisms: exploring the paths between conflict and cooperation. Trends Ecol Evol. 1999;14:49-53

42. Frank AC, Saldierna Guzmán JP, Shay JE. Transmission of bacterial endophytes. Microorganisms. 2017:5:70.

43. Liu H, Carvalhais LC, Crawford M, Singh E, Dennis PG, et al. Inner plant values: diversity, colonization and benefits from endophytic bacteria. Front Microbiol. 2017;8:2552.

44. Franceschi VR, Loewus FA. Oxalate biosynthesis and function in plants and fungi. In: Calcium oxalate in biological systems; 1995. p. 113-30.

45. Franceschi VR, Nakata PA. Calcium oxalate in plants: formation and function. Annu Rev Plant Biol. 2005;56:41-71.

46. Foster AS. Plant idioblasts: remarkable examples of cell specialization. Protoplasma. 1956:46:184-93.

47. Bahadur B, Vyaya Bhaskar K, Earooqui SM. LM and SEM studies of seed coat in five species of Oxalis L.(Oxalidaceae). Proc Indian Natl Sci Acad B. 1983;49:348-53.

48. Sahin N. Isolation and characterization of a diazotrophic, oxalateoxidizing bacterium from sour grass (Oxalis pes-caprae L.). Res Microbiol. 2005:156:452-6

49. Lodewyckx C, Vangronsveld J, Porteous F, Moore ER, Taghavi S, et al. Endophytic bacteria and their potential applications. Crit Rev Plant Sci. 2002; 21:583-606.
50. Bashan Y, De-Bashan LE. Plant growth-promoting. Encyclopedia Soils Environ. 2005:1:103-15.

51. Bacilio-Jiménez M, Aguilar-Flores S, del Valle MV, Pérez A, Zepeda A, et al. Endophytic bacteria in rice seeds inhibit early colonization of roots by Azospirillum brasilense. Soil Biol Biochem. 2001;33:167-72.

52. Puente ME, Li CY, Bashan Y. Endophytic bacteria in cacti seeds can improve the development of cactus seedlings. Environ Exp Bot. 2009;66:402-8.

53. Rout ME, Chrzanowski TH, Westlie TK, DeLuca TH, Callaway RM, et al. Bacterial endophytes enhance competition by invasive plants. Am J Bot. 2013;100:1726-37

54. Ryan RP, Germaine K, Franks A, Ryan DJ, Dowling DN. Bacterial endophytes: recent developments and applications. FEMS Microbiol Lett. 2008;278:1-9.

55. Truyens S, Weyens N, Cuypers A, Vangronsveld J. Bacterial seed endophytes: genera, vertical transmission and interaction with plants. Environ Microbiol Rep. 2017:7:40-50.

56. Xu M, Sheng J, Chen L, Men Y, Gan L, et al. Bacterial community compositions of tomato (Lycopersicum esculentum Mill.) seeds and plant growth promoting activity of ACC deaminase producing Bacillus subtilis (HYT-12-1) on tomato seedlings. World J Microbiol Biotechnol. 2014;30:835-45.

57. Ramesh A, Sharma SK, Sharma MP, Yadav N, Joshi OP. Inoculation of zinc solubilizing Bacillus aryabhattai strains for improved growth, mobilization and biofortification of zinc in soybean and wheat cultivated in Vertisols of Central India. Appl Soil Ecol. 2014;73:87-96.

58. Arvind G, Sood S, Rahi P, Thakur R, Chauhan S, et al. Diversity analysis of diazotrophic bacteria associated with the roots of tea (Camellia sinensis ( $L$.) O. Kuntze). J Microbiol Biotechnol. 2011:21:545-55.

59. Ding Y, Wang J, Liu Y, Chen S. Isolation and identification of nitrogenfixing bacilli from plant rhizospheres in Beijing region. J Appl Microbiol. 2005;99:1271-81.

60. Xie G, Su B, Cui Z. Isolation and identification of N2-fixing strains of Bacillus in rice rhizosphere of the Yangtze River valley. Wei Sheng Wu Xue Bao. 1998;38:480-3.

61. Rojas A, Holguin G, Glick BR, Bashan Y. Synergism between Phyllobacterium sp.(N2-fixer) and Bacillus licheniformis (P-solubilizer), both from a semiarid mangrove rhizosphere. FEMS Microbiol Ecol. 2001:35:181-7.

62. Kang SM, Radhakrishnan R, You YH, Joo GJ, Lee IJ, et al. Phosphate solubilizing Bacillus megaterium mj1212 regulates endogenous plant carbohydrates and amino acids contents to promote mustard plant growth. Indian J Microbiol. 2014:54:427-33.

63. Nongkhlaw W, Mary F, Joshi SR. Epiphytic and endophytic bacteria that promote growth of ethnomedicinal plants in the subtropical forests of Meghalaya, India. Rev Biol Trop. 2014;62:1295-308.

64. Rashid S, Charles TC, Glick BR. Isolation and characterization of new plant growth-promoting bacterial endophytes. Appl Soil Ecol. 2012;61:217-24.

65. Schwartz AR, Ortiz I, Maymon M, Herbold CW, Fujishige NA, et al. Bacillus simplex - a little known PGPB with anti-fungal activity - alters pea legume root architecture and nodule morphology when coinoculated with Rhizobium leguminosarum bv. viciae. Agronomy. 2013:3:595-620.

66. Downing KJ, Leslie G, Thomson JA. Biocontrol of the sugarcane borer Eldana saccharina by expression of the Bacillus thuringiensis cry $1 \mathrm{Ac} 7$ and Serratia marcescens chiA genes in sugarcane-associated bacteria. Appl Environ Microbiol. 2000;66:2804-10.

67. Bai Y, Zhou X, Smith DL. Enhanced soybean plant growth resulting from coinoculation of Bacillus strains with Bradyrhizobium japonicum. Crop Sci. 2003:43:1774-81.

\section{Publisher's Note}

Springer Nature remains neutral with regard to jurisdictional claims in published maps and institutional affiliations. 